\title{
Cortical thickness and sulcal depth: insights on development and psychopathology in paediatric epilepsy
}

\author{
Duygu Tosun, Prabha Siddarth, Jennifer Levitt and Rochelle Caplan
}

\section{Background}

The relationship between cortical thickness (CThick) and sulcal depth (SDepth) changes across brain regions during development. Epilepsy youth have CThick and SDepth abnormalities and prevalent psychiatric disorders.

\author{
Aims \\ This study compared the CThick-SDepth relationship in \\ children with focal epilepsy with typically developing children \\ (TDC) and the role played by seizure and psychopathology \\ variables. \\ Method \\ A surface-based, computational high-resolution three- \\ dimesional (3D) magnetic resonance image analytic \\ technique compared regional CThick-SDepth relationships in \\ 42 participants with focal epilepsy and 46 TDC (6-16 years) \\ imaged in a 1.5 Tesla scanner. Psychiatric interviews \\ administered to each participant yielded psychiatric \\ diagnoses. Parents provided seizure-related information.
}

\section{Results}

The TDC group alone demonstrated a significant negative medial fronto-orbital CThick-SDepth correlation. Focal epilepsy participants with but not without psychiatric diagnoses showed significant positive pre-central and post-central CThick-SDepth associations not found in TDC. Although the history of prolonged seizures was significantly associated with the postcentral CThick-SDepth correlation, it was unrelated to the presence/absence of psychiatric diagnoses.

\section{Conclusions}

Abnormal CThick-SDepth pre-central and post-central associations might be a psychopathology biomarker in paediatric focal epilepsy.

\section{Declaration interest}

None.

\section{Copyright and usage}

(c) 2015 The Royal College of Psychiatrists. This is an open access article distributed under the terms of the Creative Commons Non-Commercial, No Derivatives (CC BY-NC-ND) licence.
Studies on large samples of typically developing children (TDC) demonstrate that cortical thickness (CThick) increases in early childhood and decreases in late childhood and adolescence across brain regions. ${ }^{1,2}$ Parallel age-related global decrease in sulcal depth (SDepth) and increased sulcal widening of 52 youth, aged 11-15 years, were more prominent in the frontal and occipital lobes. ${ }^{3,4}$ In 923 healthy participants, aged 9-21 years, Vandekar et al found an age-related global and linear positive relationship between decreased CThick and SDepth that was associated with increased myelination in the depth of the sulci.

Children with new onset and chronic focal epilepsy have widespread age-related CThick abnormalities. ${ }^{5}$ Children with absence epilepsy do not demonstrate the normal age-related changes involving a decrease in CThick and increase in SDepth in the frontal, somatosensory and temporal regions. ${ }^{6}$ Those with new onset juvenile myoclonic epilepsy have increased CThick in frontotemporo-parietal areas. ${ }^{7}$ Children with intractable seizures also show widespread cortical thinning. ${ }^{8}$ Of note, seizure variables were unrelated to the findings in these studies.

Abnormal CThick due to delayed or impaired thinning is found in children without epilepsy who have attention-deficit hyperactivity disorder (ADHD), ${ }^{9}$ major depression, ${ }^{10}$ anxiety disorders, ${ }^{11}$ and problems with attention, ${ }^{12}$ mood, ${ }^{13}$ and social skills. ${ }^{14}$ These diagnoses and behaviour problems, prevalent in epidemiological ${ }^{15,16}$ and community studies ${ }^{17-19}$ of children with epilepsy with average IQ, are unrelated to seizure variables. Several studies have demonstrated increased cortical thinning in epilepsy youth with ADHD, behaviour problems, and anxiety disorder diagnoses. ${ }^{20-22}$

However, there have been no studies on the relationship between CThick and SDepth and whether it plays a role in the psychiatric comorbidity of children with epilepsy. Therefore, the study presented in this paper examined the following exploratory hypotheses. First, the CThick-SDepth relationship in subregions of the frontal, parietal, temporal, and occipital cortices will be different in children with focal epilepsy compared with TDC of comparable age and gender. Second, seizure variables will not be related to abnormal CThick-SDepth associations in the focal epilepsy participants. Third, we also explored whether the abnormal CThick-SDepth relationships will be evident in children with focal epilepsy compared with those without psychiatric diagnoses. Evidence for these abnormalities could begin to shed light on mechanisms underlying the psychiatric comorbidity of children with epilepsy.

\section{Method}

\section{Participants}

This study included 42 individuals with focal epilepsy (6.1-16.2 years) and 46 TDC participants (6.1-15.3 years) comparable on age and gender. Four patients, not TDC, were left-handed. Patients were included in the study if they had clinical manifestations of focal epilepsy according to the International Classification of Epilepsy ${ }^{23}$ and at least one seizure during the past year that was confirmed by a University of California Los Angeles (UCLA) board certified paediatric neurologist. We excluded patients with other epilepsy syndromes, a mixed seizure disorder, minor motor seizures, previous epilepsy surgery, a neurological illness other than epilepsy, chronic medical illness, imaging evidence for structural brain abnormalities, a metabolic disorder, a hearing disorder, IQ below 70, and bilingual speakers of American English who did not attend English-speaking schools or speak English at home. 
Patients were recruited from UCLA and University of Southern California (USC) tertiary clinics (41.9\%) and community sources, Los Angeles and Anaheim Kaiser Permanente, Los Angeles and San Diego Chapters of the Epilepsy Foundation of America, and private practices (58.1\%), as described in detail in Caplan et al. ${ }^{18}$ The parents and children's medical records provided information on age at onset, seizure frequency, current anti-epileptic drugs (AEDs), illness duration, and history of prolonged seizures $>5 \mathrm{~min}$ (Table 1). Electroencephalogram recordings done around the time of diagnosis indicated left, right, bilateral, and no lateralisation in $32.5 \%, 15 \%, 30 \%$, and $22.5 \%$ of epileptic activity respectively, which was temporal in $35 \%$, frontotemporal in $30 \%$, and not localised in $12 \%$ of the patients. Two participants (5\%) had secondary generalisation.

To include control participants from ethnic and socioeconomic status backgrounds similar to the focal epilepsy group, we recruited TDC from four public and two private Los Angeles schools. The study coordinator screened potential participants for neurological, psychiatric, language, and hearing disorders through a telephone conversation with a parent. We excluded children with a past psychiatric diagnosis or who met the criteria for a psychiatric disorder in the structured psychiatric interview, described below, once enrolled in the study.

Table 1 also presents the demographic characteristics and IQ of the study groups. Socioeconomic status was based on parental occupational and educational status, using the Hollingshead two factor index. ${ }^{24}$ Hollingshead levels I and II represent high and levels III-V represent low socioeconomic status. Other than significantly higher full-scale IQ in the TDC compared with the focal epilepsy group, the study groups did not differ significantly on age, gender, ethnicity, and socioeconomic status.

\section{Procedures}

After the procedures were fully explained, written informed consent and assent were obtained from parents and children respectively. The UCLA, USC, and Kaiser Institutional Review Boards approved the study.

\section{Psychopathology}

A psychiatrist (R.C.) or a trained research assistant administered the Kiddie Schedule for Affective Disorders and SchizophreniaPresent and Lifetime Version (K-SADS-PL) ${ }^{25}$ separately to each child and parent about the child. The child and parent often talked about the child's seizures during the interview. As a result, the interviewers were not blinded with regard to seizure disorder diagnosis. Current and lifetime Diagnostic and Statistical Manual of Mental Disorders (DSM-IV) ${ }^{26}$ diagnoses were made based on information obtained from both the child and parent interviews.

\section{Cognition}

The Wechsler Intelligence Scale for Children-Third Edition (WISC-III) ${ }^{27}$ was administered to all children to obtain a fullscale IQ score.

\section{Imaging and cortical morphometry}

Structural magnetic resonance brain image volumes were acquired on a 1.5 Tesla GE Signa scanner (GE Medical Systems, Milwaukee, WI), using a high-resolution three-dimensional (3D) T-1 weighted spoiled grass (SPGR) sequence with the following acquisition parameters: sagittal plane acquisition; slice thickness of $1.2 \mathrm{~mm}$; repetition time of $24 \mathrm{~ms}$; echo time of $9 \mathrm{~ms}$; flip angle of 22; acquisition matrix of $256 \times 192$; file-of-view of $240 \times 240 \mathrm{~mm}^{2}$, and two excitations.

The skull, scalp, extracranial tissue, cerebellum, and brain stem (at the level of the diencephalon) were removed from each image data using an automated method ${ }^{28}$ followed by a quality check. The remaining image volume was then corrected for intensity inhomogeneity using the non-parametric non-uniform intensity normalisation (N3) technique. ${ }^{29}$ Each individual's cortical surface reconstructions modelling of various layers of cortical grey matter (GM) tissue (i.e. GM and white matter interface (GM/ WM)), center of GM tissue mantle, and GM and cerebrospinal fluid interface (GM/CSF) were extracted using a cortical reconstruction method using implicit surface evolution (CRUISE) technique. ${ }^{30,31}$ Each resulting cortical surface was represented as a triangle mesh comprising of approximately 300000 mesh vertices.

CThick (Fig. 1a and b) at each point in the cortical GM tissue mantle was defined as the sum of the distances from this point to the GM/WM and GM/CSF tissue boundaries following a flow field which guarantees a one-to-one, symmetric, and continuous correspondence between the two tissue boundaries. ${ }^{32,33}$ CThick was estimated in millimeters at 3D image voxels on the GM tissue mantle. Estimated cortical thickness values were mapped onto the corresponding central cortical surface using trilinear interpolation at each mesh vertex.

Within the cortical surface reconstruction framework, sulcal regions (Fig. 1c and d) are defined as the openings surrounded by the buried, inward folded cortex. Therefore, SDepth measure was defined as a distance from the cortical surface to a reference outer cortical surface that tightly surrounds the cortical surface, outlining the exposed cortex without entering into the sulcal

\begin{tabular}{|c|c|c|c|c|}
\hline & TDC & FE & FE-Psych & FE+Psych \\
\hline$N$ & 46 & 42 & 23 & 19 \\
\hline Age, years: mean (s.d.) & $10.7(2.5)$ & $10.3(2.5)$ & $10.4(2.8)$ & $10.2(2.2)$ \\
\hline Gender, males/females, \% & $43.5 / 56.5$ & $47.6 / 52.4$ & $43.5 / 56.5$ & $55.6 / 44.4$ \\
\hline High socioeconomic status, \% & 32.6 & 31.0 & 26.1 & 33.3 \\
\hline White/non-White, \% & $43.5 / 56.5$ & $61.0 / 39.0$ & $60.9 / 39.1$ & $64.7 / 35.3$ \\
\hline Full-scale IQ (s.d.) & $111.7(14.1)^{\mathrm{a}}$ & $92.5(13.5)$ & $91.8(13 / 0)$ & $93.6(14.6)$ \\
\hline \multicolumn{5}{|l|}{ Epilepsy } \\
\hline Age at onset, years (s.d.) & NA & 6.8 (3.3) & $6.6(3.4)$ & $6.9(3.1)$ \\
\hline Seizure control, \% & NA & 48.7 & 40.0 & 61.1 \\
\hline Anti-epileptic drugs, \% & NA & & & \\
\hline None & & 2.4 & 4.4 & 0 \\
\hline Monotherapy & & 76.2 & 65.2 & 88.9 \\
\hline Polytherapy & & 21.4 & 30.4 & 11.11 \\
\hline Prolonged seizures & NA & 20 & 45.5 & 35.0 \\
\hline
\end{tabular}


3-D cortical GM tissue thickness computation

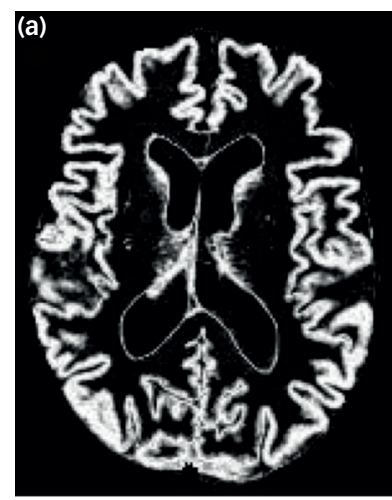

Grey matter tissue segmentation

\section{3-D sulcal depth computation}

(c)

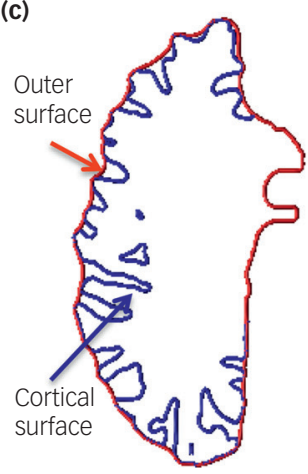

(b)

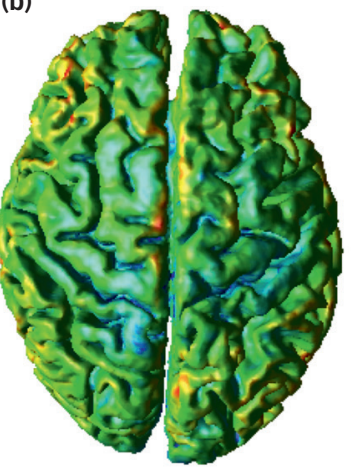

Cortical thickness mapped onto the cortical surface
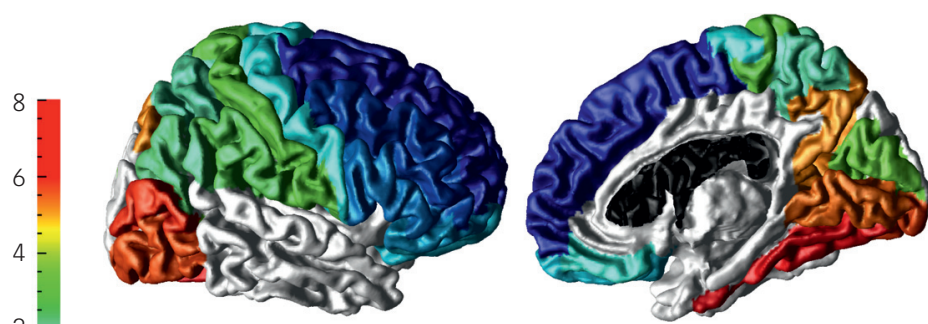

Fig. 2 A priori defined regions of interest including sulcal regions in frontal (blue hues), parietal (green hues), temporal (superior, middle, inferior), and occipital (red hues) cortices.

children with epilepsy compared with healthy control participants. ${ }^{5,6}$ These included sulcal regions in frontal (superior frontal, middle frontal, inferior frontal, lateral orbitofrontal, medial orbitofrontal, pre-central, and gyrus rectus), parietal (superior parietal, inferior parietal, supramarginal, post-central, and cuneus), temporal (superior, middle, inferior), and occipital (precuneus, lingual, inferior occipital, middle occipital, and fusiform) cortices (Fig. 2).

(d)

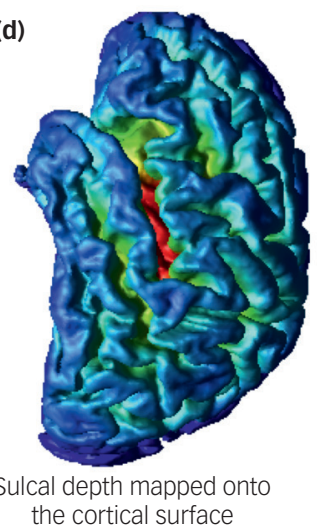

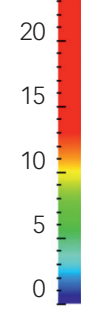

0

Fig. 1 Cortical morphometry measures: cortical thickness as the sum of the distances from each voxel on the grey matter (GM) tissue mantle to the GM/white matter (WM) and GM/cerebrospinal fluid (GM/ CSF) tissue boundaries (a) estimated in the voxel-based imaging space and (b) mapped onto cortical surface reconstruction; (c) crosssectional view of cortical surface reconstruction and the corresponding outer surface tightly surrounding this cortical surface; (d) sulcal depth measured from the cortical surface to the reference outer surface as in (c).

openings. To capture the true depth measure for the sulcal region in medial cortical surface, separate outer surfaces per cortical hemisphere were generated. Specifically, focusing on one cortical hemisphere, a geometric deformable surface model expanding the central cortical surface outwards at sulcal points was used to construct an outer cortical surface representation. ${ }^{32}$ The SDepth measure from the central cortical surface to the resulting outer cortical surfaces (one per hemisphere) was estimated.

A spherical mapping-based cortical spatial normalisation technique ${ }^{34}$ was used to match anatomically homologous cortical features between each participant's cortical surface and the cortical surface model of International Consortium for Brain Mapping high-resolution single participant template where anatomical cortical labels were defined. ${ }^{35}$ Since this is the first study to be conducted on CThick-SDepth associations in children with epilepsy, based on cortical spatial normalisation parameters, average CThick and average SDepth measures were computed on the participant's native cortical surface model in the frontal, parietal, temporal, and occipital lobes, as described in AlemánGómez et $a l^{3}$ and Vandekar et $a l^{4}$, and in subregions of interest for which we previously found differences in the CThick and SDepth of

\section{Data analysis}

Prior to statistical analyses, all data were inspected for outliers, skewness, and homogeneity of variance to ensure their appropriateness for parametric statistical tests. Children with focal epilepsy and TDC were compared on demographic measures using $t$-tests for continuous variables and chi-squared tests for categorical variables.

First, regional associations between CThick and SDepth were examined within groups using Pearson's correlations. The primary regions of interest for this study were frontal (superior frontal, middle frontal, inferior frontal, lateral fronto-orbital, medial fronto-orbital, pre-central, and gyrus rectus), parietal (superior parietal, inferior parietal, supramarginal, post-central, and cuneus), temporal (inferior temporal, middle temporal, and inferior temporal), and occipital (precuneus, lingual, inferior occipital, middle occipital, and fusiform). Due to the multiple subregions examined within each primary region, we used a significance level of 0.007 (0.05/7) for frontal (seven subregions), $0.017(0.05 / 3)$ for temporal (three subregions), and $0.01(0.05 / 5)$ for parietal and occipital (five subregions each). Further analyses were conducted only for those associations that were significant at these levels.

Within the focal epilepsy group, we examined whether seizure variables (age at seizure onset, seizure frequency, and presence of prolonged seizures) and presence of psychopathology were related to the CThick-SDepth associations. Multiple regression models were used, with regional SDepth as the dependent variable, and the same regional CThick, age at onset/seizure control/prolonged seizures, and the interaction of CThick with the seizure variables as the independent variables. In another set of regression models, instead of the seizure variables, the presence of psychiatric diagnosis and the interaction of CThick with psychiatric diagnosis were used as the independent variables. We also estimated models using regional CThick as the dependent and regional SDepth (seizure/psychopathology variable and the appropriate interaction term) as the independent variables, but the findings remained the same; hence we present only one set of findings to demonstrate the effect of seizure or psychopathology variables on the CThickSDepth associations. For those regions that exhibited a significant effect of psychiatric diagnosis on the CThick-SDepth associations, we also conducted a three-group comparison (TDC, focal epilepsy without a psychiatric diagnosis, and focal epilepsy with a psychiatric 
diagnosis) to determine the differential associations of CThick and SDepth across these three groups of participants. A significance level of 0.05 was adopted for these inferences.

\section{Results}

\section{CThick-SDepth associations in focal epilepsy and in TDC groups}

Within the TDC group, there was a significant negative CThickSDepth correlation in the medial fronto-orbital $(r=-0.42$, $P=0.005)$ region but not in the focal epilepsy group $(r=-0.009$, $P=0.9$; Fig. 3a). CThick was positively and significantly related to SDepth in the pre-central $(r=0.50, P=0.0008)$ and post-central regions $(r=0.43, P=0.004)$ of the focal epilepsy group but not in the TDC group (pre-central: $r=-0.07, P=0.7$; post-central: $r=-0.19, P=0.2)$. No other CThick-SDepth correlations for either group were significant at the levels specified.

\section{CThick-SDepth and seizure variables in focal epilepsy}

Both of the seizure variables (age at onset, seizure control, or prolonged seizures) played a role in the lack of CThick-SDepth correlation in the medial fronto-orbital region in focal epilepsy $(F(1,34)=0.5-0.8, P=0.4-0.5)$. Seizure control was not significantly related to either the pre- or post-central CThick-SDepth associations, as evidenced by the lack of significant interaction terms (pre-central: $F(1,36)=1.3, \quad P=0.3$; post-central: $\quad F(1,36)=0.03$, $P=0.9$ ). Similarly, age at onset was unrelated to both pre- and post-central CThick-SDepth associations (interaction term CThick $\times$ age at onset; pre-central: $F(1,36)=3.3, P=0.08$; postcentral: $F(1,36)=1.4, P=0.2)$.

A history of prolonged seizures was unrelated to the CThickSDepth association in the pre-central region $(F(1,36)=2.1, P=0.2)$ but was related to the CThick-SDepth correlation in the postcentral region $(F(1,36)=6.0, P=0.02)$. Post hoc testing demonstrated a positive post-central CThick-SDepth slope in the patients with (slope $=0.7, t=4.0, P=0.0003$ ) but not in those without prolonged seizures (slope $=0.02, t=0.11, P=0.9$ ). There were no significant differences in the demographic, IQ, and seizure variables of the focal epilepsy participants with and without a history of prolonged seizures (Table 2).

\section{CThick-SDepth and psychopathology in focal epilepsy}

A total of 18 (43.9\%) children in the focal epilepsy group had a psychiatric diagnosis and 24 did not (56.1\%). Of the 18 patients with a psychiatric diagnosis, 4 (9.8\%) had ADHD, 7 (17.1\%) had affective disorder (anxiety disorder and/or depression), 6 (17.6\%) a

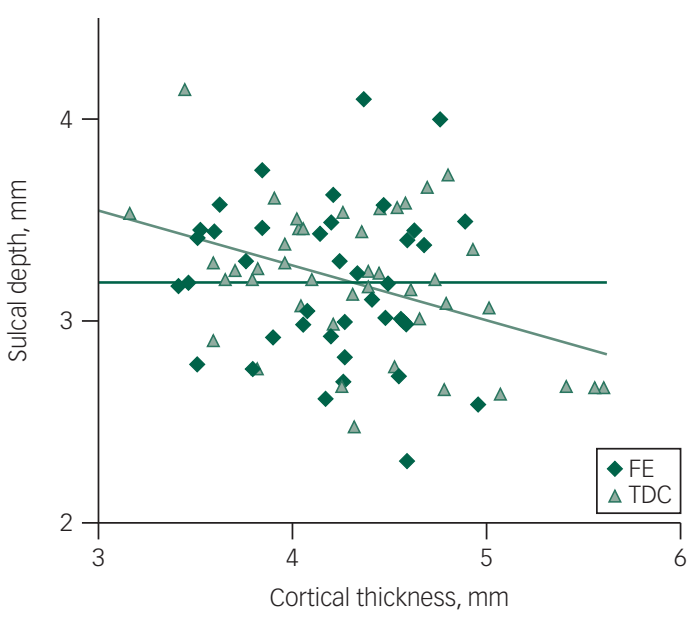

b

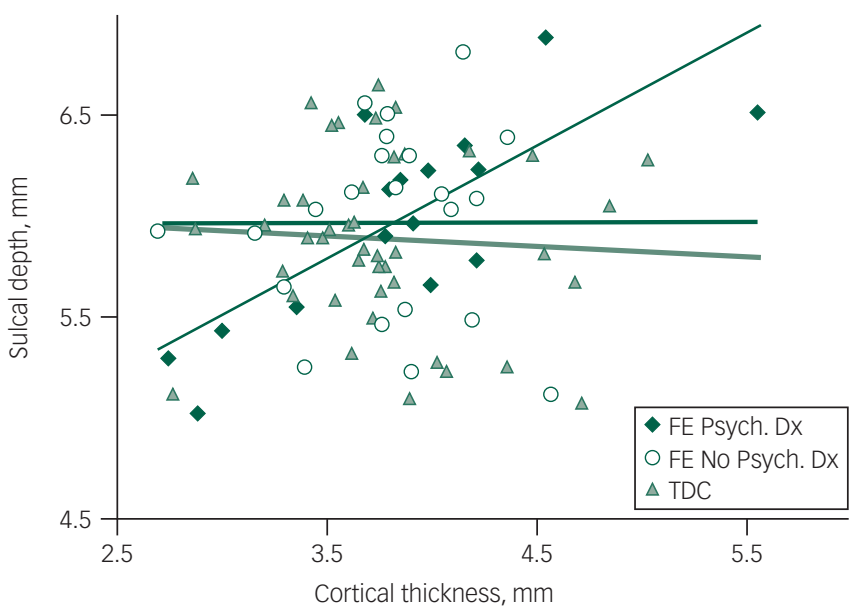

c Post-central

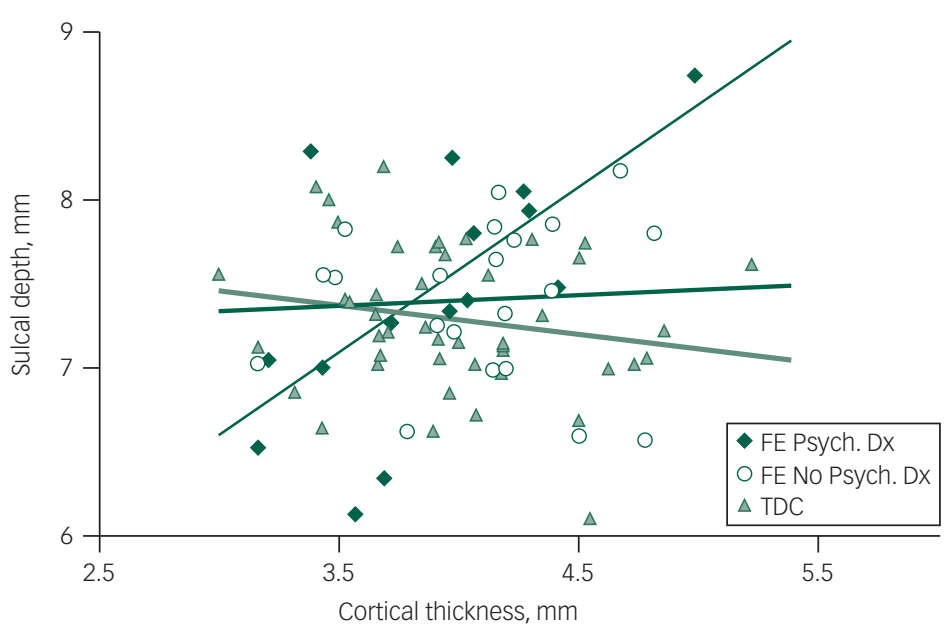

Fig. 3 Cortical thickness and sulcal depth in focal epilepsy (FE) and typically developing children (TDC) groups in the medial fronto-orbital region (a) and in the FE with and without a psychiatric diagnosis and TDC group in the pre-central (b) and post-central regions (c). 


\begin{tabular}{|c|c|c|}
\hline & $\mathrm{FE}-\mathrm{SE}$ & $\mathrm{FE}+\mathrm{SE}$ \\
\hline N & 22 & 20 \\
\hline Age, years: mean (s.d.) & $10.3(2.6)$ & $10.5(2.6)$ \\
\hline Gender, \% (M/F) & $45.0 / 55.0$ & $52.4 / 47.6$ \\
\hline High socioeconomic status, \% & 33.3 & 30.0 \\
\hline Caucasian/non-Caucasian, \% & $52.4 / 47.6$ & $73.7 / 26.3$ \\
\hline Full-scale IQ (s.d.) & $92.8(14.9)$ & $92.0(12.4)$ \\
\hline \multicolumn{3}{|l|}{ Epilepsy } \\
\hline Age at onset (s.d.) & $6.9(3.4)$ & $6.7(3.2)$ \\
\hline Seizure control, \% & 47.6 & 50.0 \\
\hline \multicolumn{3}{|l|}{ Antiepileptic drugs, \% } \\
\hline None & 4.7 & 0.0 \\
\hline Monotherapy & 81.0 & 70.0 \\
\hline Polytherapy & 14.3 & 30.0 \\
\hline
\end{tabular}

had comorbid ADHD and anxiety/affective diagnoses, and 1 (2.4\%) had other diagnoses. As evident from Table 1, there were no significant differences in the seizure variables of the focal epilepsy participants with and without a psychiatric diagnosis.

For SDepth in the pre-central region, there was a significant interaction effect of CThick $\times$ presence of a psychiatric diagnosis $(F(1,36)=4.9, P=0.03)$. Post hoc testing demonstrated a positive pre-central CThick-SDepth slope in the patients with a psychiatric diagnosis (slope $=0.5, t=3.6, P=0.0009$ ) but not in those without a psychiatric diagnosis (slope $=0.004, t=0.03, P=0.9$ ). Similarly for post-central SDepth, a significant interaction effect of CThick $\times$ presence of a psychiatric diagnosis $(F(1,36)=7.2, P=0.01)$ demonstrated that the CThick-SDepth significant association was accounted for by the focal epilepsy participants with a psychiatric diagnosis (CThick-SDepth slope $=0.9, t=3.8, P=0.0006$ ) in contrast to those without a psychiatric diagnosis (slope $=0.05, t=0.3, P=0.8$ ). Presence of psychiatric diagnosis did not play a role in the lack of medial fronto-orbital CThick-SDepth correlation in focal epilepsy $(F(1,34)=0.15, P=0.7)$.

Comparison of the CThick-SDepth associations in the three groups (TDC, focal epilepsy with a psychiatric diagnosis, and focal epilepsy without a psychiatric diagnosis) yielded a significant interaction term for both pre-central $(F(2,79)=5.0, P=0.009)$ and post-central regions $(F(2,79)=8.5, P=0.0005)$, indicating a group difference in the CThick-SDepth associations. The focal epilepsy with a psychiatric diagnosis exhibited a significant CD-SDepth association but there was no evidence of a CThick-SDepth association in either the TDC or the focal epilepsy without a psychiatric diagnosis group (Fig. $3 \mathrm{~b}$ and $\mathrm{c}$ ).

\section{Handedness}

None of the findings changed when we computed all the above analyses without the four left-handed participants with focal epilepsy.

\section{Discussion}

This is the first study to demonstrate a structural developmental abnormality involving CThick-SDepth in paediatric focal epilepsy. The significant negative CThick-SDepth association in the medial fronto-orbital region in the TDC was not found in the children with focal epilepsy. It is also the first study to demonstrate that children with focal epilepsy with a psychiatric diagnosis have an abnormal positive pre-central and post-central CThick-SDepth relationship in contrast to the patients without a psychiatric diagnosis and the TDC group. Regarding seizure variables, there was a significant positive post-central CThick-SDepth association in focal epilepsy participants with but not without a history of prolonged seizures. However, this variable, as well as age at onset and seizure frequency, was unrelated to the study's developmental and psychopathology CThick-SDepth abnormalities.

\section{CThick-SDepth and development}

The negative CThick-SDepth association in the medial frontoorbital regions of the TDC is similar to the frontal lobe findings in Alemán-Gómez et al's prospective 2-year study on 52 TDC, aged 11-15 years. ${ }^{3}$ The lack of a negative CThick-SDepth association in the medial fronto-orbital region of the focal epilepsy group suggests that focal epilepsy might affect age-related changes in CThick-SDepth associations. Given the cross-sectional nature of our study, we cannot determine whether this finding reflects a developmental delay or abnormality. Lack of involvement of the occipital lobe in the TDC's CThick-SDepth findings in our study in contrast to Alemán-Gómez et al's study might reflect our wider age range of 6-16 years, the cross-sectional study design, and methodological differences in the computation of CThick and SDepth.

Vandekar et al's ${ }^{4}$ cross-sectional study findings on 923 TDC, aged 9-21 years, demonstrated that increased myelination plays a role in the CThick-SDepth relationship in SDepths across brain regions. Although we did not examine WM, children with new onset and chronic focal epilepsy have increased WM volume ${ }^{36}$ and abnormalities in the microstructure of $\mathrm{WM}^{37}$ Studies are needed to determine whether our negative CThick-SDepth medial fronto-orbital developmental finding might represent poor myelination in focal epilepsy.

The medial fronto-orbital region subserves motivation, reward, and cognitive modulation of affect; ${ }^{38}$ theory of mind skills, such as intentionality ${ }^{39}$ and mentalising; ${ }^{40}$ as well as valuebased decision-making. ${ }^{41}$ By integrating factual and emotional information, the orbital frontal region regulates decision-making through the reappraisal of the affective or motivational importance of stimuli (see review in Happaney et $a l^{42}$ ). Structural and functional abnormalities in this brain region are associated with emotional dysregulation involving behaviours, such as impulsivity, ${ }^{43}$ aggression, ${ }^{44}$ and suicide, ${ }^{45}$ as well as psychiatric disorders, including depression, ${ }^{46}$ bipolar disorder ${ }^{47}$ schizophrenia, ${ }^{48}$ substance misuse, ${ }^{49}$ and pathological gambling. ${ }^{50}$

Several cross-sectional studies have demonstrated GM volume and thickness abnormalities in the orbital frontal region in children with new onset epilepsy $y^{20,22}$ and in those with chronic epilepsy. ${ }^{51,52}$ In light of the psychiatric, cognitive, and social skill comorbidities of paediatric epilepsy (see review in Hamiwka et $a l^{53}$ ), studies are warranted to examine the functional implications of a developmental abnormality involving the medial frontal orbital in children with focal epilepsy.

\section{Pre-central and post-central CThick-SDepth, epilepsy, and psychopathology}

Supporting our findings, one of the main predictors of brain maturity in a large TDC sample was CThick in the sensorimotor area and the other was CThick in the association areas. ${ }^{54}$ The precentral and post-central regions are involved in both paediatric and adult epilepsy. Children with temporal lobe epilepsy (TLE) ${ }^{55}$ and those with frontal lobe epilepsy ${ }^{56}$ have abnormal resting functional connectivity in these regions. Reduced functional ${ }^{57}$ and structural connectivity ${ }^{58}$ between the hippocampus and these regions in adult TLE patients and cortical thinning in adult TLE surgical candidates ${ }^{59}$ and patients who underwent surgery ${ }^{60}$ further supports the involvement of these regions in focal epilepsy. None of these child and adult studies examined the presence of psychiatric diagnoses nor excluded epilepsy patients with these 
diagnoses despite their prevalence in adult and paediatric epilepsy (see reviews in Lin et $a l^{61}$ and Hamiwka et $a l^{53}$ ).

Children with new onset seizures and ADHD, some of whom have focal epilepsy and others idiopathic generalised epilepsy, have reduced left and right pre-central and post-central CThick ${ }^{21}$ similar to children with ADHD without epilepsy. ${ }^{62}$ CThick is reduced in the left medial orbital frontal region of children with new onset epilepsy and anxiety disorder compared with healthy controls. ${ }^{22}$ To date, there have been no morphometric studies on depression in children with epilepsy. Although parent-reported broad-band and narrow-band Child Behaviour Checklist scores in children with new onset seizures were associated with widespread cortical thinning, this did not involve the pre-central and post-central regions. ${ }^{20}$

Similar to studies demonstrating no relationship of seizure variables with morphometric abnormalities ${ }^{5-8}$ and with psychopathology, ${ }^{17-19,63}$ age at onset and seizure frequency were unrelated to the pre-central and post-central CThick-SDepth and psychopathology associations. Thus, the neuropathology involved in focal epilepsy, not ongoing seizures, might underlie the psychiatric comorbidity already evident at or prior to the onset of seizures. ${ }^{64,65}$ Despite the significant positive post-central CThick-SDepth correlation in the patients with a history of prolonged seizures, this variable was unrelated to the presence/ absence of psychiatric diagnoses. If confirmed on a large focal epilepsy sample with and without a history of prolonged seizures, abnormal pre-central and post-central CThick-SDepth associations might represent a biomarker of the psychiatric comorbidity of children with focal epilepsy.

\section{Limitations}

The study included a relatively small sample of children, particularly regarding the psychopathology subgroups, with a wide age distribution, different types of psychiatric diagnoses, a history of prolonged seizures in almost half the patients, and four left-handed patients. However, the number of participants in the focal epilepsy and TDC groups was well balanced; participants were evenly distributed across the age range; and they were comparable in terms of age, gender, ethnicity, and socioeconomic status, variables that can affect morphometric measures. ${ }^{66}$ There were also no significant differences in age, IQ, and seizure variables of the focal epilepsy patients with and without a psychiatric diagnosis. Analyses of the study's hypotheses without the four left-handed participants demonstrated consistent findings. Nevertheless, the cross-sectional study design, large number of patients with prolonged seizures, and clinical heterogeneity of focal epilepsy (frontal, temporal, fronto-temporal, and no focal EEG findings) limit generalisability of the developmental findings, and underscore the need to replicate the findings in a large prospective study with comparable subgroups of patients with and without prolonged seizures.

Regarding the study's morphometric measures, we measured SDepth from the bottom of sulcus (sulcal fundi) to an outer surface tightly wrapped around the cortex. When interpreting changes in SDepth and sulcal width, it is important to consider three geometries: the gyral crown, the sulcal banks, and the sulcal fundi. If cortical pruning and thickening are not uniform across these geometries, it might translate to decreased or increased SDepth depending on the relative change in the gyral crown and sulcal fundi. Although these three geometries contribute to the SDepth measure we used, we did not differentiate between them as done in Vandekar et al. ${ }^{4}$

We used a conservative method to establish significance of the findings because of the large number of brain regions for which we studied CThick and SDepth.
Finally, unrelated to seizure variables, children with focal epilepsy and average intelligence have a developmental abnormality involving a lack of a significant negative medial fronto-orbital CThick-SDepth relationship. A positive pre-central and post-central CThick-SDepth association, evident in focal epilepsy patients with a psychiatric diagnosis, might be a biomarker of psychiatric comorbidity in paediatric focal epilepsy.

Duygu Tosun, PhD, Department of Radiology and Biomedical Imaging, University of California - San Francisco, California, and Center for Imaging of Neurodegenerative Diseases, San Francisco Veterans Affairs Medical Center, San Francisco, California, USA; Prabha Siddarth, PhD, Department of Psychiatry, Semel Institute for Neuroscience and Human Behavior, UCLA David Geffen School of Medicine, Los Angeles, California, USA; Jennifer Levitt, MD, Department of Psychiatry, Semel Institute for Neuroscience and Human Behavior, UCLA David Geffen School of Medicine, LoS Angeles, California, USA: Rochelle Caplan, MD, Department of Psychiatry, Semel Institute for Neuroscience and Human Behavior, UCLA David Geffen School of Medicine, Los Angeles, California, USA

Correspondence: Duygu Tosun, Centre for Imaging of Neurodegenerative Diseases, VA Medical Center, Bldg 13, 114M, San Francisco, CA 94121, USA. Email: duygu.tosun@ ucsf.edu

First received 3 Jul 2015, final revision 31 Aug 2015, accepted 1 oct 2015

\section{References}

1 Raznahan A, Shaw P, Lalonde F, Stockman M, Wallace GL, Greenstein D, et al. How does your cortex grow? J Neurosci 2011; 31: 7174-7.

2 Shaw $\mathrm{P}$, Kabani NJ, Lerch JP, Eckstrand K, Lenroot R, Gogtay N, et al. Neurodevelopmental trajectories of the human cerebral cortex. J Neurosci 2008; 28: 3586-94.

3 Alemán-Gómez Y, Janssen J, Schnack H, Balaban E, Pina-Camacho L, AlfaroAlmagro $F$, et al. The human cerebral cortex flattens during adolescence. J Neurosci 2013; 33: 15004-10.

4 Vandekar SN, Shinohara RT, Raznahan A, Roalf DR, Ross M, DeLeo N, et al. Topologically dissociable patterns of development of the human cerebral cortex. J Neurosci 2015; 35: 599-609.

5 Tosun D, Caplan R, Siddarth $\mathrm{P}$, Seidenberg M, Gurbani S, Toga AW, et al. Intelligence and cortical thickness in children with complex partial seizures. Neuroimage 2011; 15: 337-46.

6 Tosun D, Siddarth P, Toga AW, Hermann B, Caplan R. Effects of childhood absence epilepsy on associations between regional cortical morphometry and aging and cognitive abilities. Hum Brain Mapp 2010; 32: 580-91.

7 Lin JJ, Dabbs K, Riley JD, Jones JE, Jackson DC, Hsu DA, et al. Neurodevelopment in new-onset juvenile myoclonic epilepsy over the first 2 years. Ann Neurol 2014; 76 : $660-8$.

8 Widjaja E, Mahmoodabadi SZ, Snead OC, Almehdar A, Smith ML. Widespread cortical thinning in children with frontal lobe epilepsy. Epilepsia 2011; 52: 1685-91.

9 Duerden EG, Tannock R, Dockstader C. Altered cortical morphology in sensorimotor processing regions in adolescents and adults with attention-deficit/ hyperactivity disorder. Brain Res 2012; 1445: 82-91.

10 Reynolds S, Carrey N, Jaworska N, Langevin LM, Yang XR, Macmaster FP. Cortical thickness in youth with major depressive disorder. BMC Psychiatry 2014; 14: 83.

11 Strawn JR, Wegman CJ, Dominick KC, Swartz MS, Wehry AM, Patino LR, et al. Cortical surface anatomy in pediatric patients with generalized anxiety disorder J Anxiety Disord 2014; 28: 717-23.

12 Ducharme S, Hudziak JJ, Botteron KN, Albaugh MD, Nguyen TV, Karama S, et al Decreased regional cortical thickness and thinning rate are associated with inattention symptoms in healthy children. I Am Acad Child Adolesc Psychiatry 2012; 51: 18-27.e2.

13 Ducharme S, Albaugh MD, Hudziak JJ, Botteron KN, Nguyen TV, Truong C, et al. Anxious/depressed symptoms are linked to right ventromedial prefrontal cortical thickness maturation in healthy children and young adults. Cereb Cortex 2014; 24: $2941-50$

14 Levan A, Baxter L, Kirwan CB, Black G, Gale SD. Right frontal pole cortical thickness and social competence in children with chronic traumatic brain injury: Cognitive proficiency as a mediator. J Head Trauma Rehabil 2015; 30: E24-31.

15 Hesdorffer DC, Lúdvígsson P, Hauser WA, Olafsson E, Kjartansson O. Cooccurrence of major depression or suicide attempt with migraine with aura and risk for unprovoked seizure. Epilepsy Res 2007; 75: 220-3. 
16 Hesdorffer DC, Ludvigsson P, Olafsson E, Gudmundsson G, Kjartansson O, Hause WA. ADHD as a risk factor for incident unprovoked seizures and epilepsy in children. Arch Gen Psychiatry 2004; 61: 731-6.

17 Austin JK, Perkins SM, Johnson CS, Fastenau PS, Byars AW, desGrauw TJ, et al. Behavior problems in children at time of first recognized seizure and changes over the following 3 years. Epilepsy Behav 2011; 21: 373-81.

18 Caplan R, Siddarth P, Gurbani S, Ott D, Sankar R, Shields WD. Psychopathology and pediatric complex partial seizures: seizure-related, cognitive, and linguistic variables. Epilepsia 2004; 45: 1273-81.

19 Jones JE, Watson R, Sheth R, Caplan R, Koehn M, Seidenberg M, et al. Psychiatric comorbidity in children with new onset epilepsy. Dev Med Child Neurol 2007; 49 493-7.

20 Dabbs K, Jones JE, Jackson DC, Seidenberg M, Hermann BP. Patterns of cortica thickness and the child behavior checklist in childhood epilepsy. Epilepsy Behav 2013; 29: 198-204.

21 Saute R, Dabbs K, Jones JE, Jackson DC, Seidenberg M, Hermann BP. Brain morphology in children with epilepsy and ADHD. PLOS One 2014; 9: e95269.

22 Jones JE, Jackson DC, Chambers KL, Dabbs K, Hsu DA, Stafstrom CE, et al. Children with epilepsy and anxiety: subcortical and cortical differences. Epilepsia 2015; 56: 283-90

23 Engel J Jr, International League Against Epilepsy (ILAE). A proposed diagnostic scheme for people with epileptic seizures and with epilepsy: report of the ILAE task force on classification and terminology. Epilepsia 2001; 42: 796-803.

24 Hollingshead AB. Medical sociology: a brief review. Milbank Mem Fund Q Health SOC 1973; 51: 531-42

25 Kaufman J, Birmaher B, Brent D, Rao U, Flynn C, Moreci P, et al. Schedule for affective disorders and schizophrenia for school age children present and lifetime version (K SADS PL): initial reliability and validity data. J Am Acad Child AdolesC Psychiatry 1997; 36: 980-8.

26 American Psychiatric Association. Diagnostic and Statistical Manual of Menta Disorders. 4th edn (DMS-IV) ed. APA, 1994.

27 Wechsler D. Wechsler Intelligence Scale for Children, 3rd edn. The Psychologica Corporation, 1991.

28 Shattuck DW, Leahy RM. Brainsuite: an automated cortical surface identification tool. Med Image Anal 2002; 6: 129-42.

29 Sled JG, Pike GB. Standing-wave and RF penetration artifacts caused by elliptic geometry: an electrodynamic analysis of MRI. IEEE Trans Med Imaging 1998; 17 $653-62$

30 Han X, Pham DL, Tosun D, Rettmann ME, XU C, Prince JL. Cruise: cortica reconstruction using implicit surface evolution. Neuroimage 2004; 23: 997-1012.

31 Tosun D, Rettmann ME, Naiman DQ, Resnick SM, Kraut MA, Prince JL. Cortica reconstruction using implicit surface evolution: accuracy and precision analysis. Neuroimage 2006; 29: 838-52.

32 Tosun $D$, Duchesne $S$, Rolland $Y$, Toga AW, Vérin $M$, Barillot $C$. 3-D analysis of cortical morphometry in differential diagnosis of Parkinson's plus syndromes: mapping frontal lobe cortical atrophy in progressive supranuclear palsy patients. Med Image Comput Comput Assist Interv 2007; 10: 891-9.

33 Yezzi AJ Jr, Prince JL. An Eulerian PDE approach for computing tissue thickness. IEEE Trans Med Imaging 2003; 22: 1332-9.

34 Tosun D, Prince JL. A geometry-driven optical flow warping for spatial normalization of cortical surfaces. IEEE Trans Med Imaging 2008; 27: 1739-53.

35 Holmes CJ, Hoge R, Collins L, Woods R, Toga AW, Evans AC. Enhancement of MR images using registration for signal averaging. J Comput Assist Tomogr 1998; 22 324-33

36 Tosun D, Dabbs K, Caplan R, Siddarth P, Toga A, Seidenberg M, et al. Deformationbased morphometry of prospective neurodevelopmental changes in new onset paediatric epilepsy. Brain 2011; 134: 1003-14.

37 Ciumas $C$, Saignavongs $M$, Ilski F, Herbillon V, Laurent A, Lothe A, et al. White matter development in children with benign childhood epilepsy with centrotemporal spikes. Brain 2014; 137: 1095-106.

38 Amft M, Bzdok D, Laird AR, Fox PT, Schilbach L, Eickhoff SB. Definition and characterization of an extended social-affective default network. Brain Struct Funct 2015; 220: 1031-49.

39 Powell $\mathrm{J}$, Lewis PA, Dunbar Rl, García-Fiñana M, Roberts N. Orbital prefronta cortex volume correlates with social cognitive competence. Neuropsychologia 2010; 48: 3554-62.

40 Lewis PA, Rezaie R, Brown R, Roberts N, Dunbar RI. Ventromedial prefronta volume predicts understanding of others and social network size. Neuroimage 2011; 57: 1624-9.

41 McNamee D, Rangel A, O'Doherty JP. Category-dependent and categoryindependent goal-value codes in human ventromedial prefrontal cortex. Nat Neurosci 2013; 16: 479-85.
42 Happaney K, Zelazo PD, Stuss DT. Development of orbitofrontal function: current themes and future directions. Brain Cogn 2004; 55: 1-10.

43 Gansler DA, McLaughlin NCR, Iguchi L, Jerram M, Moore DW, Bhadelia R, et al. A multivariate approach to aggression and the orbital frontal cortex in psychiatric patients. Psychiatry Res 2009; 171: 145-54.

44 Hoptman MJ, D’Angelo D, Catalano D, Mauro CJ, Shehzad ZE, Kelly AM, et al. Amygdalofrontal functional disconnectivity and aggression in schizophrenia. Schizophr Bull 2010; 36: 1020-8.

45 Caplan R, Siddarth P, Levitt J, Gurbani S, Shields WD, Sankar R. Suicidality and brain volumes in pediatric epilepsy. Epilepsy Behav 2010; 18: 286-90.

46 Mak A, Wong MM, Han SH, Lee TM. Gray matter reduction associated with emotion regulation in female outpatients with major depressive disorder: a voxel-based morphometry study. Progr Neuro-Psychopharmacol Biol Psychiatry 2009; 33: $1184-90$.

47 Nait $\mathrm{P}$, Nicoletti $\mathrm{M}$, Chen $\mathrm{HH}$, Hatch JP, Caetano SC, Sassi RB, et al. Anatomical measurements of the orbitofrontal cortex in child and adolescent patients with bipolar disorder. Neurosci Lett 2007; 413: 183-6.

48 Hoptman MJ, Volavka J, Weiss EM, Czobor P, Szeszko PR, Gerig G, et al. Quantitative MRI measures of orbitofrontal cortex in patients with chronic schizophrenia or schizoaffective disorder. Psychiatry Res 2005; 140: 133-45.

49 Verdejo-García A, Bechara A. A somatic marker theory of addiction. Neuropharmacology 2009; 56: 48-62.

50 Ko CH, Liu G-C, Hsiao S, Yen JY, Yang MJ, Lin WC, et al. Brain activities associated with gaming urge of online gaming addiction. J Psychiatr Res 2009; 43: 739-47.

51 Caplan R, Levitt J, Siddarth P, Taylor J, Daley M, Wu KN, et al. Thought disorder and frontotemporal volumes in pediatric epilepsy. Epilepsy Behav 2008; 13: 593-9.

52 Daley M, Levitt J, Siddarth P, Mormino E, Hojatkashani C, Gurbani S, et al. Frontal and temporal volumes in children with epilepsy. Epilepsy Behav 2007; 10: 470-6.

53 Hamiwka L, Jones JE, Salpekar J, Caplan R. Child psychiatry: special edition on the future of clinical epilepsy research. Epilepsy Behav 2011; 22: 38-46.

54 Khundrakpam BS, Tohka J, Evans AC. Prediction of brain maturity based on cortical thickness at different spatial resolutions. Neuroimage 2015; 111: 350-9.

55 Mankinen $\mathrm{K}$, Jalovaara $\mathrm{P}$, Paakki JJ, Harila M, Rytky S, Tervonen $\mathrm{O}$, et al. Connectivity disruptions in resting-state functional brain networks in children with temporal lobe epilepsy. Epilepsy Res 2012; 100: 168-78.

56 Widjaja E, Zamyadi M, Raybaud C, Snead OC, Smith ML. Abnormal functional network connectivity among resting-state networks in children with frontal lobe epilepsy. AJNR Am J Neuroradiol 2013; 34: 2386-92.

57 Haneef Z, Lenartowicz A, Yeh HJ, Levin HS, Engel J Jr, Stern JM. Functional connectivity of hippocampal networks in temporal lobe epilepsy. Epilepsia 2014: 55: $137-45$.

58 Voets NL, Beckmann CF, Cole DM, Hong S, Bernasconi A, Bernasconi N, et al. Structural substrates for resting network disruption in temporal lobe epilepsy. Brain 2012; 135: 2350-7.

59 McDonald CR, Hagler DJ, Ahmadi ME, Tecoma E, Iragui V, Gharapetian L, et al. Regional neocortical thinning in mesial temporal lobe epilepsy. Epilepsia 2008; 49 794-803.

60 Lin JJ, Salamon N, Lee AD, Dutton RA, Geaga JA, Hayashi KM, et al. Reduced neocortical thickness and complexity mapped in mesial temporal lobe epilepsy with hippocampal sclerosis. Cereb Cortex 2007; 17: 2007-18.

61 Lin JJ, Mula M, Hermann BP. Uncovering the neurobehavioural comorbidities of epilepsy over the lifespan. Lancet 2012; 380: 1180-92.

62 Shaw P, Malek M, Watson B, Sharp W, Evans A, Greenstein D. Development of of cortical surface area and gyrification in attention-deficit/hyperactivity disorder. Biol Psychiatry 2012; 72: 191-7.

63 Caplan R, Siddarth P, Stahl L, Lanphier E, Vona P, Gurbani S, et al. Childhood absence epilepsy: behavioral, cognitive, and linguistic comorbidities. Epilepsia 2008; 49: 1838-46

64 Austin JK, Dunn DW, Caffrey HM, Perkins SM, Harezlak J, Rose DF. Recurrent seizures and behavior problems in children with first recognized seizures: a prospective study. Epilepsia 2002; 43: 1564-73.

65 Hermann BP, Jones JE, Sheth R, Koehn M, Becker T, Fine J, et al. Growing up with epilepsy: a two-year investigation of cognitive development in children with new onset epilepsy. Epilepsia 2008; 49: 1847-58.

66 Noble KG, Houston SM, Kan E, Sowell ER. Neural correlates of socioeconomic status in the developing human brain. Dev SCi 2012; 15: 516-27. 